Article

\title{
Continuous Renal Replacement Therapy with High Flow Rate Can Effectively, Safely, and Quickly Reduce Plasma Ammonia and Leucine Levels in Children
}

\author{
Fatih Aygun ${ }^{1, *(\mathbb{D}}$, Fatih Varol ${ }^{1}$, Cigdem Aktuglu-Zeybek ${ }^{2}{ }^{\circledR}$, Ertugrul Kiykim ${ }^{2}$ and Halit Cam ${ }^{1}$ \\ 1 Department of Pediatric Intensive Care Unit, Istanbul University-Cerrahpasa, Cerrahpasa Medical Faculty, \\ Fatih, Istanbul 34098, Turkey; dr_fvarol@yahoo.com (F.V.); hacam@istanbul.edu.tr (H.C.) \\ 2 Division of Nutrition and Metabolism, Department of Pediatrics, Cerrahpasa Medical Faculty, \\ Istanbul University-Cerrahpasa, Istanbul 34098, Turkey; dracaz@istanbul.edu.tr (C.A.-Z.); \\ ertugrulkiykim@hotmail.com (E.K.) \\ * Correspondence: faygun9@hotmail.com; Tel.: +90-(532)532-786-86-82; Fax: +90-(212)-6328633
}

Received: 12 February 2019; Accepted: 1 April 2019; Published: 4 April 2019

check for updates

\begin{abstract}
Introduction: Peritoneal dialysis and continuous renal replacement therapy (CRRT) are the most frequently used treatment modalities for acute kidney injury. CRRT is currently being used for the treatment of several non-renal indications, such as congenital metabolic diseases. CRRT can efficiently remove toxic metabolites and reverse the neurological symptoms quickly. However, there is not enough data for CRRT in children with metabolic diseases. Therefore, we aimed a retrospective study to describe the use of CRRT in metabolic diseases and its associated efficacy, complications, and outcomes. Materials and Methods: We performed a retrospective analysis of the records of all patients admitted in the pediatric intensive care unit (PICU) for CRRT treatment. Results: Between December 2014 and November 2018, 97 patients were eligible for the present study. The age distribution was between 2 days and 17 years, with a mean of $3.77 \pm 4.71$ years. There were 13 (36.1\%) newborn with metabolic diseases. The patients were divided into two groups: CRRT for metabolic diseases and others. There was a significant relationship between the groups, including age $(p \leq 0.001)$, weight $(p=0.028)$, blood flow rate $(p \leq 0.001)$; dialysate rate $(p \leq 0.001)$, and replacement rate $(p \leq 0.001)$. The leucine reduction rate was $3.88 \pm 3.65$ (\% per hour). The ammonia reduction rate was $4.94 \pm 5.05$ in the urea cycle disorder group and $5.02 \pm 4.54$ in the organic acidemia group. The overall survival rate was $88.9 \%$ in metabolic diseases with CRRT. Conclusion: In particularly hemodynamically unstable patients, CRRT can effectively and quickly reduce plasma ammonia and leucine.
\end{abstract}

Keywords: mapple syrup urine disease; continuous renal replacement therapy; hyperammonemia; neonate

\section{Introduction}

Peritoneal dialysis and continuous renal replacement therapy (CRRT) are the most frequently used treatment modalities for acute kidney injury in critically ill children. CRRT is currently being used for the treatment of several non-renal indications, such as metabolic acidosis and congenital metabolic diseases [1]. Because patients with inborn errors of metabolism have a high risk of hemodynamic instability due to low weight, usage of drugs such as arginine and lower systemic pressure etc., CRRT is accepted as a better choice than intermittent hemodialysis for treatment [2,3].

Continuous venovenous hemofiltration $(\mathrm{CVVH})$, continuous venovenous hemodialysis (CVVHD), and hemodiafiltration (CVVHDF) have been used successfully in critically ill children since 1970s [4]. 
However, it is more widely used in the treatment of metabolic coma in recent years. CRRT is a treatment choice for metabolic coma in children, as it allows rapidly, continuous and programmed removal of toxic metabolites, which is tolerated better hemodynamically $[5,6]$. There are some differences from intermittent hemodialysis. With intermittent hemodialysis, clearance is limited by blood flow rates [7]. Furthermore, when intermittent HD is discontinued, there may be a rebound effect. However, much better clearance values and less rebound effect have been reported with CRRT [8]. In the literature, mortality, dialysis dependence, and effectivity were similar to these CRRT modalities (CVVH, CVVHD, and CVVHDF) $[6,8]$.

During life-threatening acute metabolic crisis, plasma toxic metabolite concentrations like ammonia and branched amino acids should be reduced as soon as possible [2]. Hyperammonemia is observed in metabolic disorders such as urea cycle disorders (UCD), organic acidemias and fatty acid oxidation defects. Increased ammonia levels causing neurological symptoms can be detected in various inborn errors of metabolism (IEM). CRRT has been reported as an effective way of ammonia removal and reversal of neurological symptoms [9].

Maple syrup urine disease (MSUD) is an inherited disorder of branched chain amino acids (BCAA) caused by defective ketoacid dehydrogenase complex. Infants with classic MSUD, the most severe form, present within the first few days of life with irritability, poor feeding, lethargy, intermittent apnea, opisthotonus, abnormal movements, coma, and encephalopathy. The toxic accumulation of BCAA, mostly leucine, is associated with the appearance of neurological symptoms. Early treatment is essential to prevent neurotoxicity and death $[9,10]$. CRRT is a choice of treatment in metabolic crisis of MSUD resistant to conservative treatment modalities including nutritional support [1,11].

There is not enough data for CRRT in children with metabolic diseases. Also, the most appropriate and effective dialysis technique in the pediatric intensive care unit (PICU) has not been determined yet. The aim of this retrospective study is to describe the efficacy, complications and outcome of CRTT in IEMs.

\section{Materials and Methods}

\subsection{Study Design}

We conducted a single-center, retrospective study in a 7-bed PICU tertiary care hospital with two isolation rooms, 6 ventilators and two Prismaflex ${ }^{\mathrm{TM}}$ hemofiltration machines (Baxter, Deerfield, IL, USA). The study included critically ill children 2 days-18 years of age who underwent CRRT from December 2014 to November 2018. Ethical approval for this study was obtained from the Local Ethics Committee (December 2018, No. 29430533-903.99.-92611).

\subsection{Patient Population and Data Collection}

We performed a retrospective analysis of the records of all patients admitted in the PICU between December 2014 and November 2018. Patients with a history of chronic renal failure and PICU stay duration of $<24 \mathrm{~h}$ and those who died on the first day of admission were excluded. All data were obtained from electronic and written medical records in accordance with the ethical principles for medical research (Figure 1).

Demographic data and reason of hospitalization were recorded. The patients' sex and age, underlying disease, invasive or non-invasive mechanical ventilation (NIV) requirement, inotropic drug usage, red blood cell transfusion, duration of hospitalization in the intensive care unit, mortality, plasma exchange, catheter diameter, and hemodialysis filters were recorded (Table 1). 


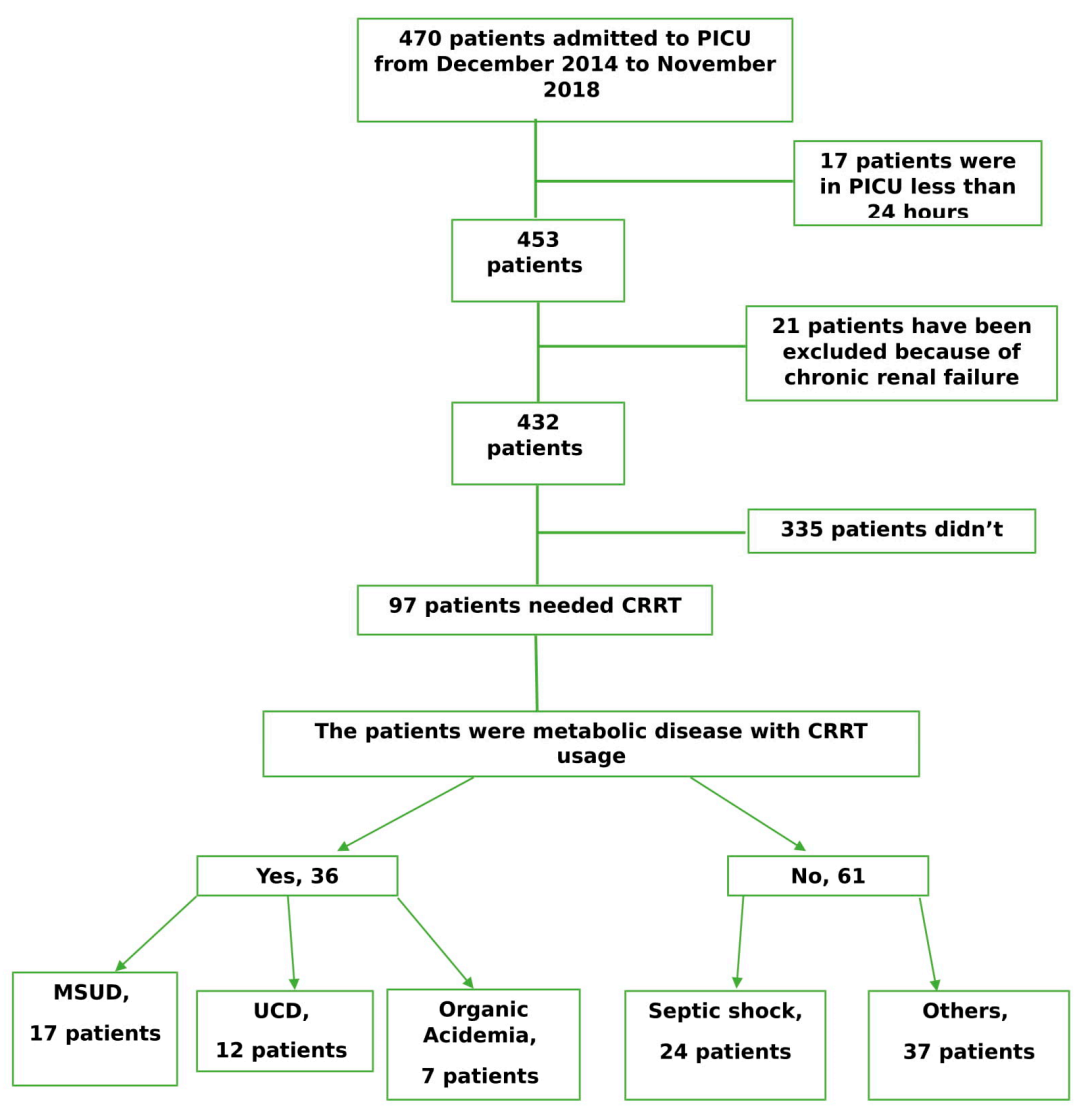

Figure 1. Cohort flow.

Table 1. Demographic characteristics of the CRRT ${ }^{1}$ patients in the PICU ${ }^{2}$.

\begin{tabular}{|c|c|}
\hline Number of Patients & $(n=97)$ \\
\hline Gender & $n(\%)$ \\
\hline Male & $55(56.7 \%)$ \\
\hline Female & $42(43.3 \%)$ \\
\hline \multicolumn{2}{|l|}{ Underlying Disease before the CRRT Use } \\
\hline Metabolic disease & $36(37.1 \%)$ \\
\hline Septic shock & $24(24.7 \%)$ \\
\hline Respiratory disease & $10(10.3 \%)$ \\
\hline Neurological disease & $4(4.1 \%)$ \\
\hline Cardiovascular Disease & $4(4.1 \%)$ \\
\hline Intoxication & $2(2.1 \%)$ \\
\hline Trauma & $2(2.1 \%)$ \\
\hline Hematology-oncology-related diagnosis & $3(3.1 \%)$ \\
\hline Acute renal pathology & $12(12.4 \%)$ \\
\hline Age (years) & Mean \pm S.D. \\
\hline 2 days -17.5 years & $(4.15 \pm 4.91)$ \\
\hline Prognostic Factors & $n(\%)$ \\
\hline Red Blood Cell transfusion & $67(69.1 \%)$ \\
\hline Inotropic medication & $49(50.5 \%)$ \\
\hline Mechanical Ventilation & $41(42.3 \%)$ \\
\hline NIV $^{3}$ & $35(36.1 \%)$ \\
\hline Plasma Exchange & $23(23.7 \%)$ \\
\hline Death & $14(14.4 \%)$ \\
\hline Duration of Stay in PICU (d) & $8.61 \pm 7.08$ \\
\hline Duration of CRRT application (hours) & $55.07 \pm 79.62$ \\
\hline
\end{tabular}


Table 1. Cont.

\begin{tabular}{|c|c|}
\hline Number of Patients & $(n=97)$ \\
\hline \multicolumn{2}{|l|}{ Catheters' Diameter } \\
\hline 6.5 and $7 \mathrm{Fr}$ & $15(15.5 \%)$ \\
\hline $8 \mathrm{Fr}$ & $62(63.9 \%)$ \\
\hline $10 \mathrm{Fr}$ & $9(9.3 \%)$ \\
\hline 11.5 & $11(11.3 \%)$ \\
\hline \multicolumn{2}{|l|}{ Hemodialysis Filter } \\
\hline $0.2 \mathrm{~m}^{2}$ & $13(13.4 \%)$ \\
\hline $0.6 \mathrm{~m}^{2}$ & $70(72.2 \%)$ \\
\hline $0.9 \mathrm{~m}^{2}$ & $14(14.4 \%)$ \\
\hline
\end{tabular}

\subsection{Catheterization and Continuous Renal Replacement Therapy (CRRT)}

The CRRT indications included fluid overload, electrolyte imbalance, metabolic acidosis, inherited metabolic diseases metabolic disease, and intoxication. Some patients had more than one indication. Double-lumen central venous catheters were percutaneously placed along the femoral vein, jugular vein, or subclavian vein by a single specialist. Primarily, jugular and femoral catheters were inserted due to the potential complications such as pneumothorax and hemothorax. The catheter was dilatated by the dilatator of the 4-Fr catheter and then by dilatators of the 7-Fr and 8-Fr catheters. We used $4 \mathrm{Fr}$ catheters as guide and used the smallest possible hemodialysis catheter. The location of all jugular and subclavian catheters was controlled by chest X-ray. The right side of the patient was favored for the insertion of the jugular and subclavian catheters due to decreased complication risk.

All patients received sedation and analgesia prior to catheterization. Midazolam, ketamine, and remifentanil were preferred for sedation and analgesia. Lidocaine was used as a local anesthetic. Neuromuscular blockers were not used. Surgical catheters were not attached (cut down etc.). The aseptic method was used during catheterization. The entry location was sterilized with $1 \%$ povidone-iodine and left to dry. Disposable sterile covers that covered the whole body were used. A sterile apron, mask and bonnet were used. The catheters were attached with the Seldinger method and fixed to the skin with 2.0 sharp-pointed silk sutures. Ultrasonography (USG) was not used.

Anticoagulation was performed using unfractionated heparin. The dosage of heparin was adjusted on the basis of the activated partial thromboplastin time (aPTT), which was checked every $4 \mathrm{~h}$ and maintained at 60-80 s. Prismaflex ${ }^{\mathrm{TM}}$ hemofiltration systems and poly membrane (AN69) filters were used. The blood flow rate was $5-20 \mathrm{~mL} / \mathrm{kg} / \mathrm{min}$. The dialysate rate, replacement fluid rate, and ultrafiltration rate were adjusted on the basis of the patients' diagnoses. The dialysate flow rates were set between 2 and 12.9 L/1.73 m²/h. Multibic ${ }^{\text {TM }}$ (Fresenius Medical Care, AG Co., Bad Hamburg, Germany) was used as dialysate solution. We used CVVHD and CVVHDF.

Patients with body weight less than $5 \mathrm{~kg}$ underwent blood priming and the system was subjected to internal hemodialysis for $10 \mathrm{~min}$ to prevent bradykinin release and electrolyte instability. The dialysis sets were filled with $5 \%$ albumin for patients having hemodynamic instability and body weighth $>5 \mathrm{~kg}$. The blood priming bag included red blood cells mixed 1:1 with normal saline.

We used unfractionated heparin for anticoagulation. The dosage of heparin was arranged according to partial thromboplastin time (aPTT) that was checked every $4 \mathrm{~h}$, keeping aPTT in 60-80 s. Blood gas, ammonia, electrolyte, serum leucine, and coagulation controls were taken from all patients for every $4 \mathrm{~h}$.

\subsection{Support Treatment for Metabolic Diseases}

All of the patients were given high energy to prevent the catabolic process. Intravenous thiamine supplementation was provided for patients with MSUD. For patients with hyperammonemi; arginine, 
citrulline, carboglu (carglumic acid) and sodium benzoate support were supplied. Lipid solution was started in all patients before the CRRT. All patients received intravenous phosphorus and calcium supplements.

\subsection{Definition of Acute Kidney Injury}

Acute kidney injury was defined as oliguria (urine output $<0.5 \mathrm{~mL}$ per $\mathrm{kg}$ of body weight per $\mathrm{h}$ ) and an elevated serum creatinine value for the patient's age, or a 1.5-fold increase in the baseline creatinine level in $24 \mathrm{~h}$. The estimated glomerular filtration rate was calculated according to the original Schwartz Formula. In addition, while serum urea and creatinine levels were measured, the glomerular filtration rate (GFR) was also controlled additionally which is a routine procedure of our laboratory.

\subsection{CRRT for Metabolic Disease}

In this study, an indication for CRRT was considered for ammonia concentrations $>400 \mu \mathrm{mol} / \mathrm{L}$ and leucine concentrations $>700 \mu \mathrm{mol} / \mathrm{L}$. In addition, CRRT was started for metabolic diseases with unexplained encephalopathy.

The patients were divided into two groups: CRRT for metabolic disease and others. The groups were compared. The patients' demographic, prognostic, and laboratory parameters in the admission were recorded. Laboratory parameters, and C-reactive protein, leukocyte, lymphocyte, platelet counts, and electrolytes in the first $24 \mathrm{~h}$ were considered as the possible risk factors of CRRT.

The patients with metabolic diseases were divided into three groups. These were MSUD, urea cycle disorder (UCD), and organic acidemias. The groups were compared.

\subsection{Statistical Analysis}

Statistical analysis was performed using the IBM SPSS 21.0 (SPSS Inc., Chicago, IL, USA). Continuous variables were expressed as means \pm standard deviations and categorical variables as frequencies (percentages). Student's $t$-test was used for continuous variables with a normal distribution. Pearson's chi-square test and analysis of variance (ANOVA) were used for the comparison of the categorical data between the groups. A $p$-value of $<0.05$ was considered statistically significant.

\section{Results}

\subsection{Demographics}

Between December 2014 and November 2018, 97 patients were found eligible for the present study. Of the 97 patients, 55 (56.7\%) were boys, and 42 (43.3\%) were girls. The age distribution was between 2 days and 17 years, with a mean of $3.77 \pm 4.71$ years. The mean duration of hospitalization in the PICU was $8.61 \pm 7.08$ days.

Overall, metabolic decompensation/attack, septic shock, and respiratory failure were the main indications of CRRT. Inotropic drugs were used in 49 (50.5\%) CRRT patients. MV was used in $41(42.3 \%)$ CRRT patients, and NIV was efficient in $35(36.1 \%)$ patients. Plasma exchange was performed in $23(23.7 \%)$ patients. Fourteen (14.4\%) CRRT patients died during their PICU stay. The demographic data of the CRRT patients are shown in Table 1.

Furthermore, 6.5-Fr (Able ${ }^{\circledR}$, Oriontama Jaya, Indonesia) and 7-Fr (Medcomp ${ }^{\mathrm{TM}}$, Harleysville, PA USA) hemodialysis catheters were used in 15 patients; 8-Fr hemodialysis catheters (Mahurkar ${ }^{\mathrm{TM}}$, Medtronic, Minneapolis, MN, USA) in 62 patients; 10-Fr hemodialysis catheters (Mahurkar ${ }^{\mathrm{TM}}$ ) in 9 patients; and 11.5-Fr hemodialysis catheters (Mahurkar ${ }^{\mathrm{TM}}$ ) in 11 patients. Prismaflex ${ }^{\mathrm{TM}} \mathrm{M} 60$ (Baxter, Deerfield, IL, USA) used as the hemodialysis filter in 70 patients; Prismaflex ${ }^{\mathrm{TM}}$, M100 in 14 patients; and Prismaflex ${ }^{\mathrm{TM}} \mathrm{HF} 20$ in 13 patients. 


\subsection{Comparison of the CRRT Usage with or Without Metabolic Disease in Pediatric Intensive Care Unit (PICU)}

The patients were divided into two groups: CRRT for metabolic diseases and others. There was a significant relationship between these groups, including age $(p \leq 0.001)$, weight $(p=0.028)$, NIV $(p=0.028)$, red blood cell (RBC) transfusion $(p=0.005)$, plasma exchange $(p \leq 0.001)$, lymphocyte count $(p=0.008)$, platelet count $(p \leq 0.001), \operatorname{CRP}(p=0.008)$, and calcium level $(p=0.006)$. There was also a significant relationship between CRRT for metabolic disease and blood flow rate $(p \leq 0.001)$; dialysate rate $(p \leq 0.001)$; replacement rate $(p \leq 0.001)$; catheter sizes $(p \leq 0.001)$, and hemodialysis filters $(p \leq 0.001)$. There were $13(36.1 \%)$ newborn who were used CRRT for metabolic diseases. There was no relationship in mortality between the groups. (Table 2).

Table 2. Comparison of clinical and laboratory findings for CRRT patients with and without metabolic disease.

\begin{tabular}{|c|c|c|c|}
\hline Metabolic Disease with CRRT ${ }^{1}$ & Yes $(n=36)$ Mean \pm S.D. & No $(n=61)$ Mean \pm S.D. & $p$-Value \\
\hline \multicolumn{4}{|l|}{ Gender } \\
\hline Male & $22(61.1 \%)$ & $33(54.1 \%)$ & \multirow[b]{2}{*}{0.501} \\
\hline Female & $14(38.9 \%)$ & $28(45.9 \%)$ & \\
\hline \multicolumn{4}{|l|}{ Prognostic factors } \\
\hline Age (years) & $1.01 \pm 1.16$ & $6.00 \pm 5.32$ & $\leq 0.001$ \\
\hline Weight (kg) & $9.62 \pm 8.19$ & $23.13 \pm 21.30$ & 0.028 \\
\hline Mechanical ventilation & $17(47.2 \%)$ & $24(39.3 \%)$ & 0.448 \\
\hline Inotropic drug usage & $19(52.8 \%)$ & $30(49.2 \%)$ & 0.732 \\
\hline Noninvasive mechanical ventilation & $14(38.9 \%)$ & $21(34.4 \%)$ & 0.028 \\
\hline Red blood cell transfusion & $31(86.1 \%)$ & $36(59.0 \%)$ & 0.005 \\
\hline Duration of stay in the PICU ${ }^{2}$ (days) & $8.86 \pm 8.68$ & $8.47 \pm 12.37$ & 0.867 \\
\hline Plasma exchange & $3(8.3 \%)$ & $20(32.8 \%)$ & $<0.001$ \\
\hline Newborn & $13(36.1 \%)$ & $0(0 \%)$ & $\leq 0.001$ \\
\hline Mortality & $4(11.1 \%)$ & $10(16.4 \%)$ & 0.474 \\
\hline Heart rate on admission $(/ \mathrm{min})$ & $136.11 \pm 22.56$ & $147.00 \pm 25.42$ & 0.202 \\
\hline Respiratory rate on admission $(/ \mathrm{min})$ & $35.33 \pm 7.91$ & $43.73 \pm 12.57$ & 0.012 \\
\hline \multicolumn{4}{|l|}{ Laboratory findings } \\
\hline Leukocyte count $\left(10^{3} / \mu \mathrm{L}\right)$ & $9987.6 \pm 5591.2$ & $11584.4 \pm 10569.6$ & 0.514 \\
\hline Lymphocyte count $\left(10^{3} / \mu \mathrm{L}\right)$ & $4842.2 \pm 3651.5$ & $2397.2 \pm 2824.4$ & 0.008 \\
\hline Platelet count $\left(10^{3} / \mu \mathrm{L}\right)$ & $280000 \pm 139449$ & $157181 \pm 113465$ & $\leq 0.001$ \\
\hline C-reactive protein level (mg/dL) & $1.87 \pm 2.99$ & $5.79 \pm 9.45$ & 0.008 \\
\hline Sodium level $(\mathrm{mmol} / \mathrm{L})$ & $137.30 \pm 6.12$ & $138.08 \pm 9.08$ & 0.721 \\
\hline Chlorine level (mmol/L) & $98.96 \pm 9.59$ & $100.64 \pm 11.21$ & 0.591 \\
\hline Magnesium level (mg/dL) & $1.87 \pm 0.36$ & $2.02 \pm 0.34$ & 0.301 \\
\hline Calcium level (mg/dL) & $9.06 \pm 0.92$ & $8.18 \pm 1.24$ & 0.006 \\
\hline \multicolumn{4}{|l|}{ Parameters and settings of CRRT } \\
\hline Duration of CRRT (hours) & $36.42 \pm 81.17$ & $58.77 \pm 52.14$ & 0.104 \\
\hline Blood flow rate $(\mathrm{mL} / \mathrm{min})$ & $6.67 \pm 2.24$ & $4.79 \pm 0.58$ & $\leq 0.001$ \\
\hline Dialysate rate $\left(\mathrm{mL} / 1.73 \mathrm{~m}^{2} / \mathrm{h}\right)$ & $6076.03 \pm 2383.95$ & $1995.83 \pm 32.28$ & $\leq 0.001$ \\
\hline Replacement rate $(\mathrm{mL} / \mathrm{kg} / \mathrm{h})$ & $45.06 \pm 13.13$ & $35.19 \pm 6.32$ & $\leq 0.001$ \\
\hline \multicolumn{4}{|l|}{ Catheter sizes } \\
\hline 6.5 and $7 \mathrm{Fr}$ & $10(27.8 \%)$ & $5(12.2 \%)$ & \multirow{4}{*}{$\leq 0.001$} \\
\hline $8 \mathrm{Fr}$ & $26(72.2 \%)$ & $36(59.0 \%)$ & \\
\hline $10 \mathrm{Fr}$ & 0 & $9(14.8 \%)$ & \\
\hline 11.5 and $12 \mathrm{Fr}$ & 0 & $11(18.0 \%)$ & \\
\hline \multicolumn{4}{|l|}{ Hemodialysis filters } \\
\hline $0.2 \mathrm{~m}^{2}$ & $11(30.6 \%)$ & $2(3.3 \%)$ & \multirow{3}{*}{$\leq 0.001$} \\
\hline $0.6 \mathrm{~m}^{2}$ & $25(69.4 \%)$ & $45(73.8 \%)$ & \\
\hline $0.9 \mathrm{~m}^{2}$ & 0 & $14(22.9 \%)$ & \\
\hline \multicolumn{4}{|l|}{ Mod of CRRT } \\
\hline CVVHDF $^{3}$ & $32(88.9 \%)$ & $59(96.7 \%)$ & \multirow[b]{2}{*}{0.122} \\
\hline CVVHD $^{4}$ & $4(11.1 \%)$ & $2(3.3 \%)$ & \\
\hline
\end{tabular}

${ }^{1}$ Continuous renal replacement therapy; ${ }^{2}$ patients in pediatric intensive care unit (PICU); ${ }^{3}$ continuous venovenous hemodiafiltration ${ }^{4}$ continuous venovenous hemodialysis. 
The patients with metabolic diseases were divided into three groups: MSUD, UCD, and organic acidemia. There was a significant relationship between metabolic disease groups and demographic-prognostic factors, inotropic drug usage $(p \leq 0.001)$, NIV $(p=0.003)$, RBC transfusion $(p=0.039)$, duration of stay in the PICU $(p \leq 0.001)$, blood flow rate $(p=0.002)$, and replacement rate $(p=0.018)$ (Table 3$)$.

Table 3. Comparison of clinical findings in CRRT patients with metabolic disease.

\begin{tabular}{|c|c|c|c|c|}
\hline & $\begin{array}{l}\text { MSUD }^{1} \\
(n=17)\end{array}$ & $\begin{array}{l}\text { Urea Cycle Disorder } \\
\qquad(n=12)\end{array}$ & $\begin{array}{c}\text { Organic Acidemia } \\
*(n=7)\end{array}$ & $p$-Value \\
\hline Sex (male) & $11(64.7 \%)$ & $8(66.7 \%)$ & $3(42.9 \%)$ & 0.541 \\
\hline Age (years) & $1.25 \pm 1.27$ & $0.87 \pm 1.18$ & $0.68 \pm 0.78$ & 0.480 \\
\hline Weight $(\mathrm{kg})$ & $9.80 \pm 11.04$ & $9.35 \pm 5.87$ & $10.10 \pm 8.77$ & 0.988 \\
\hline Mechanical ventilation & $5(29.4 \%)$ & $7(58.3 \%)$ & $5(71.4 \%)$ & 0.111 \\
\hline Inotropic drug usage & $3(17.6 \%)$ & $11(91.7 \%)$ & $5(71.4 \%)$ & $\leq 0.001$ \\
\hline Noninvasive mechanical ventilation & $4(23.5 \%)$ & $3(25.0 \%)$ & $7(100 \%)$ & 0.003 \\
\hline Blood component transfusion & $12(70.6 \%)$ & $12(100 \%)$ & $7(100 \%)$ & 0.039 \\
\hline Duration of stay in the PICU ${ }^{2}$ (days) & $3.94 \pm 3.07$ & $10.92 \pm 7.76$ & $17.29 \pm 11.98$ & $\leq 0.001$ \\
\hline Mortality & $0(0 \%)$ & $2(16.7 \%)$ & $2(28.6 \%)$ & 0.097 \\
\hline Duration of CRRT ${ }^{3}$ (hours) & $22.53 \pm 17.84$ & $19.42 \pm 16.43$ & $35.00 \pm 13.30$ & 0.144 \\
\hline Blood flow rate $(\mathrm{ml} / \mathrm{min})$ & $7.81 \pm 2.17$ & $4.91 \pm 0.94$ & $7.25 \pm 2.22$ & 0.002 \\
\hline Dialysate rate $\left(\mathrm{ml} / 1.73 \mathrm{~m}^{2} / \mathrm{h}\right)$ & $6225 \pm 2196$ & $6083 \pm 2690$ & $5550 \pm 2695$ & 0.864 \\
\hline Replacement rate $(\mathrm{ml} / \mathrm{kg} / \mathrm{h})$ & $41.07 \pm 13.42$ & $53.17 \pm 9.88$ & $38.17 \pm 11.23$ & 0.018 \\
\hline \multirow{3}{*}{ Age distribution } & $6(35.3 \%)$ & $6(50.0 \%)$ & $1(14.3 \%)$ & \multirow{3}{*}{0.187} \\
\hline & $7(41.2 \%)$ & $5(41.7 \%)$ & $6(85.7 \%)$ & \\
\hline & $4(23.5 \%)$ & $1(8.3 \%)$ & $0(0 \%)$ & \\
\hline
\end{tabular}

${ }^{1}$ MSUD: maple syrup urine disease, ${ }^{2}$ PICU: pediatric intensive care unit, ${ }^{3}$ CRRT: continuous renal replacement therapy, *: without MSUD.

The values of toxic metabolites were recorded before and after the procedure in patients who underwent CRRT due to metabolic diseases. The mean leucine level was $1777.0 \pm 831.6 \mu \mathrm{mol} / \mathrm{L}$ at the beginning and $222.1 \pm 143.5 \mu \mathrm{mol} / \mathrm{L}$ at the end of CRRT in the MSUD group. The mean ammonia level was $1143.5 \pm 1069.9 \mu \mathrm{mol} / \mathrm{L}$ at the beginning and $50.0 \pm 7.07 \mu \mathrm{mol} / \mathrm{L}$ at the end of the patients with UCD.

The ammonia reduction rate was $3.93 \pm 3.68$ (per hour) in the MSUD group, $4.94 \pm 5.05$ (per hour) in the UCD group, and $5.02 \pm 4.54$ (per hour) in the organic acidemia group. The leucine reduction rate was $3.88 \pm 3.65$ (\% per hour) (Table 4$)$.

Table 4. The changes of metabolites level in metabolic diseases when CRRT.

\begin{tabular}{lccc}
\hline & $\begin{array}{c}\text { MSUD }^{\mathbf{1}} \\
(\boldsymbol{n}=\mathbf{1 7})\end{array}$ & $\begin{array}{c}\text { UCD }^{2} \\
(\boldsymbol{n}=\mathbf{1 2})\end{array}$ & $\begin{array}{c}\text { Organic Acidemia * } \\
(\boldsymbol{n}=\mathbf{7})\end{array}$ \\
\hline Ammonia (start the CRRT $\left.{ }^{3}\right)(\mu \mathrm{mol} / \mathrm{L})$ & $164.8 \pm 145.5$ & $1143.5 \pm 1069.9$ & $538.6 \pm 1017.9$ \\
Ammonia (end of the CRRT) $(\mu \mathrm{mol} / \mathrm{L})$ & $57.7 \pm 51.4$ & $50.0 \pm 7.07$ & $71.23 \pm 55.1$ \\
Ammonia reduction rate $(\%$ per hour) & $3.93 \pm 3.68$ & $4.94 \pm 5.05$ & $5.02 \pm 4.54$ \\
Leucine (start the CRRT) $(\mu \mathrm{mol} / \mathrm{L})$ & $1777.0 \pm 831.6$ & - & - \\
Leucine (end of the CRRT) $(\mu \mathrm{mol} / \mathrm{L})$ & $222.1 \pm 143.5$ & - & - \\
Leucine reduction rate $(\%$ per hour) & $3.88 \pm 3.65$ & - & - \\
Duration of CRRT (hours) & $22.53 \pm 17.84$ & $19.42 \pm 16.43$ & $35.00 \pm 13.30$ \\
\hline
\end{tabular}

${ }^{1}$ Maple syrup urine disease, ${ }^{2}$ urea cycle disorder,${ }^{3}$ continuous renal replacement therapy, ${ }^{*}$ without MSUD.

Changes in serum ammonia levels during CRRT in patients with UCD are shown in Figure 2. There was rapid decrease in serum ammonia in the first hours, which was followed by a slow decline, as seen in the Figure 2. Six patients in the UCD group had serum ammonia level $>1000 \mu \mathrm{mol} / \mathrm{L}$, the decrease rate of ammonia level was faster in that group compared to the other UCD patients. Only two patients with UCD had ammonia level $>500 \mu \mathrm{mol} / \mathrm{L}$ at the 12 th hour. 


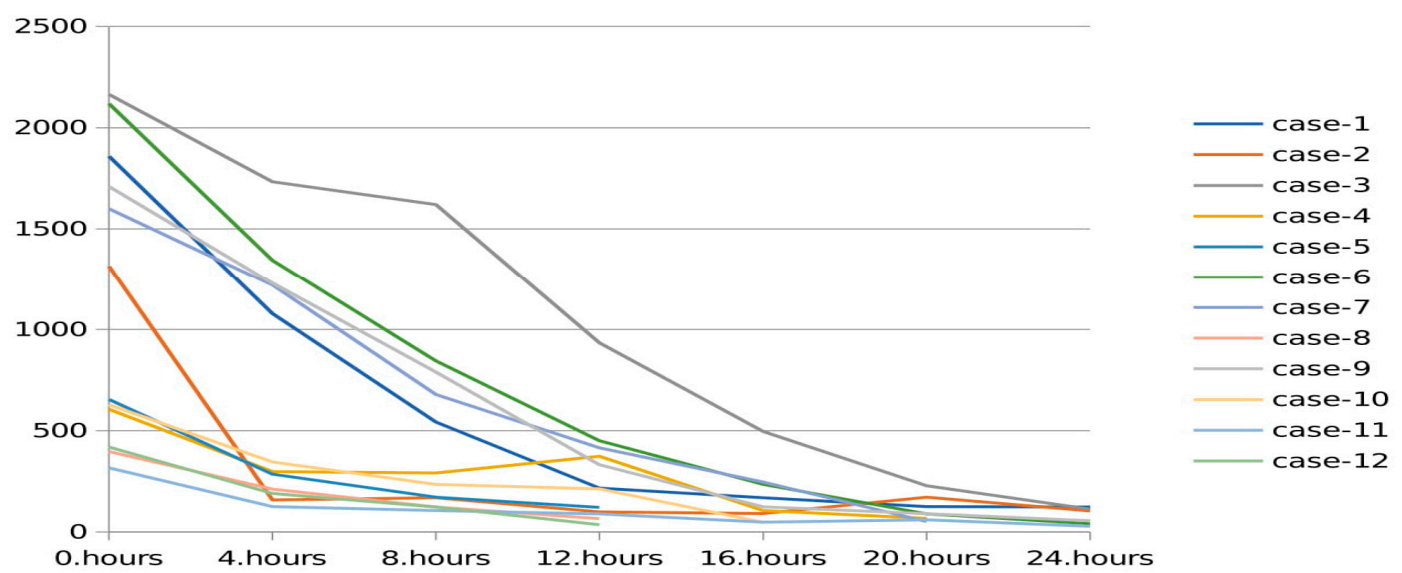

Figure 2. Changes in serum ammonia levels during CRRT in patients with urea cycle disorders.

\subsection{Survival Analysis for Patients with CRRT Usage}

Eighty-three (85.6\%) patients were still alive after discharge from PICU. In the Kaplan-Meier analysis, there was no significant relationship between CRRT patients with or without metabolic disease $(p=0.414)$ (Figure 3). The mean overall survival time was $25.29 \pm 1.69$ days in CRRT patients with metabolic disease.

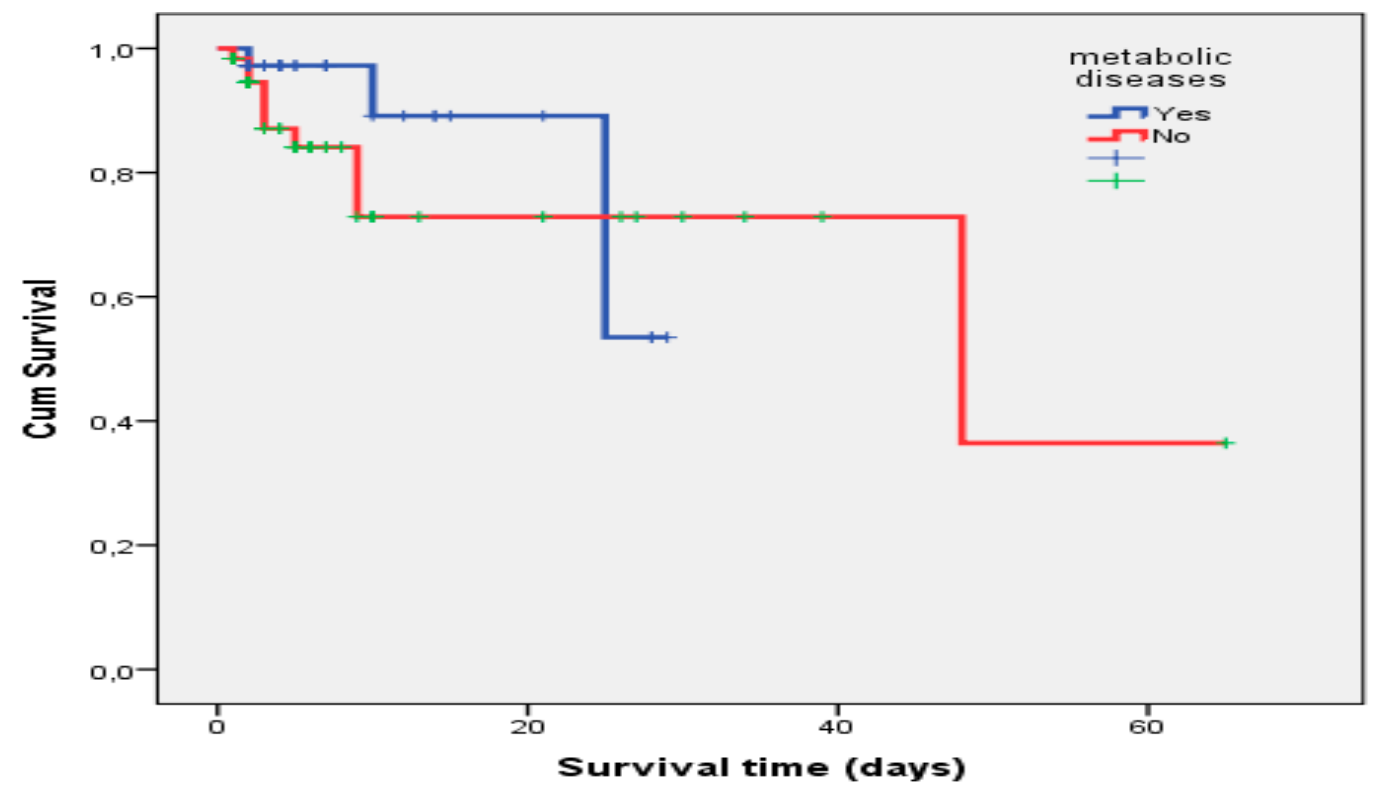

Figure 3. Kaplan-Meier survival curve of the patients with and without CRRT usage for metabolic diseases.

\subsection{Complications in the Patients with Metabolic Disease}

We experienced some complications during the CRRT performance in PICU. The most common complication was anemia and thrombocytopenia for newborns. Eight newborns developed thrombocytopenia that required transfusion during CRRT. Blood priming was applied to all patients having body weight less $5 \mathrm{~kg}$ and red blood cell transfusion was performed. None of the patients experienced serious life-threatening bleeding disorder such as intracranial or gastrointestinal.

Two patients with UCD died because of sepsis, they had sepsis on admission. One patient died due to thromboembolism that developed at the end of CRRT. There was no complication during catheter insertion. Catheters of patients with hyperammonemia were not removed after hemodialysis due to probable risk of rebound recurrence. No catheter-related infections or sepsis were observed. 
In total 19 patients used to have inotrope during CRRT. Before starting CRRT, blood or albumin priming was performed in order not to impair blood pressure and hemodynamics. None of these complications were associated with high dialysate flow rate.

All the patients were followed by the pediatric nutrition and metabolism department, after discharged. In addition, concurrent follow-up was performed in the pediatric neurology department. The neurological outcome of patients with MSUD was good. However, patients with OCD and organic academia developed slight neurological influences. There were no patients with severe mental retardation and cerebral palsy.

\section{Discussion}

In our study, it was found that CRRT was effective and safe treatment of metabolic diseases in children. It was used in $36(37.1 \%)$ patients for metabolic decompensates. Only four patients with metabolic diseases died. Although higher blood flow rate, dialysate rate and replacement rate were used in the metabolic group, serious complications were not detected during CRRT. MSUD patients required less inotropic drugs, had shorter PICU stay duration and none of the patients died during the follow up. There were no patients with severe mental retardation and cerebral palsy.

Several different metabolic diseases including urea cycle defects and organic acidemias can cause hyperammonemia in children [12]. Ammonia is an extreme neurotoxic metabolite in the human body. Prolonged persistence of elevated ammonia levels can cause astrocyte swelling, brain oedema, coma, severe disability, and even death. Thus, emergency treatment of hyperammonemia must be initiated before neurologic damage occurs $[12,13]$. The medical treatment of hyperammonemia begins with high-dose dextrose infusion to prevent catabolism. Cessation of protein consumption, higher caloric intake, insulin, carnitine, vitamins, and sodium benzoate/phenyl butyrate are used for treatment of hyperammonemia [14]. However, medical treatment modalities do not act sufficiently quickly to lower very high ammonia levels. Therefore, CRRT has been recommended to rapidly reduce the ammonia levels $[7,11,15]$. In the literature, the most important indicator of prognosis has been found to be the duration of hyperammonemia before the start of CRRT [16]. Currently, there is no consensus as to when it is appropriate to initiate dialysis in clinically significant hyperammonemia [17]. Indication for CRRT is considered for ammonia concentrations $>400 \mu \mathrm{mol} / \mathrm{L}$ [2]. We used this indication in our study and 19 of 97 (19.6\%) children received CRRT for hyperammonemia. We treated with sodium benzoate/phenyl butyrate, vitamins, high dextrose containing fluid (12-16 mg/kg/sc) with insulin and lipid infusion before the CRRT. CRRT was initiated, if the plasma ammonia level was $>400 \mathrm{mmol} / \mathrm{L}$ despite treatment or if encephalopathy due to hyperammonemia developed.

In the literature, Picca et al. reported that CVVHD mode was the optimal modality for extracorporeal ammonium detoxification [15]. CVVHDF was used for all of our patients with hyperammonemia and our CRRT clearance was very high (5\%). Interestingly, CRRT duration was longer in patients with organic acidemia. The reason for this was persistent metabolic (lactic) acidosis. Especially in two patients, CRRT was lasted more than $48 \mathrm{~h}$. In our study, at first, we preferred CVVHD for MSUD, because MSUD is a benign disease compared with hyperammonemia. However, after 4 patients, we used CVVHDF because we thought it would be more effective. Therefore, we preferred CVVHD only in 4 patients. In the literature, there was no difference in survival when the patients were grouped according to the type of membrane or CRRT modality (CVVH, CVVHD or CVVHDF) [6,18]. In addition, mortality and dialysis dependence were similar between CVVH and CVVHDF groups [18]. Therefore, we used CVVHDF in our patients to benefit from both dialysate and filtration effect. The most important factor in our choice of CRRT was to prevent the rebound effect that is reported in the intermittent hemodialysis (HD). By contrast, McBryde et al. suggested that intermittent HD should be the first-line RRT modality for the treatment of metabolic diseases, with CRRT used to prevent rebound only after HD is discontinued [19].

The most important feature of our study that it was been used the higher rate of dialysate and replacement fluids during CRRT than others studies. We have used higher dialysate flow rate rather 
than the usual uses of acute kidney injury. Because, in a prospective study has demonstrated that slower reductions in ammonia levels may worsen long-term outcomes [20]. Therefore, we have kept dialysate rates higher than standard CRRT usage. Dialysate flow rate was $6083 \pm 2690 \mathrm{~mL} / 1.73 \mathrm{~m}^{2} / \mathrm{h}$ for the patients with UCDs and $5550 \pm 2695 \mathrm{~mL} / 1.73 \mathrm{~m}^{2} / \mathrm{h}$ for the patients with organic acidemias. High-flow dialysate rate was found very effective for reducing ammonia in our study. The ammonia reduction rates were almost $5 \%$ per $h$. This ratio seems a little low. We think there are two reasons for this. First, initial ammonia levels were $<500 \mu \mathrm{mol} / \mathrm{L}$ in some patients. Second, in the first hours of dialysis, ammonia dropped much faster as seen in Figure 2.

In this study, we also slowly decreased the dialysis rate to avoid rebound upon the cessation of CRRT. There were a few rebound increases in plasma ammonia level after cessation of CRRT. None of our patients required CRRT due to rebound increase in ammonia level. Like our study, Hanudel et al. reported CRRT use consisting first of a dialysate flow rate of $5000 \mathrm{~mL} / \mathrm{h}$ to rapidly decrease plasma ammonia levels in newborns [16]. In an another newborn study, it was revealed that high-dose CRRT for neonatal hyperammonemia was an effective and safe method for reducing ammonia [7].

We set higher dialysis speed for patients admitted with metabolic coma than other disease. To prevent electrolyte disorders that may arise from high flow dialysate rate, we monitored the serum biochemistry every $4 \mathrm{~h}$. Multibic 4.0 dialysate solution containing $4 \mathrm{mmol}$ of potassium was used in the patients with metabolic diseases. We did not encounter serious biochemical problems while monitoring our patients.

Increased plasma concentration of branched chain amino acids, mainly leucine, is associated with neurological symptoms and neonatal encephalopathy [10]. Peritoneal and intermittent hemodialysis are less effective and more dangerous than CRRT especially in low weight infants [21]. If the catabolic state of the patient continues at the end of dialysis, the leucine levels continue to increase due to the rebound effect of intermittent hemodialysis. CRRT may not lead to this rebound phenomenon because of longer duration use. In this study, we used high flow rate CRRT that rapidly reduced leucine levels. Our leucine removal rate was faster and safe like the literature [22]. By contrast with the hyperammonemia, there was no second session of CRRT used in our MSUD patients. In addition, duration of stay in the PICU was shorter than hyperammonemia. There was no died in our MSUD patients due to CRRT use. In addition, these patients had very good neurological outcomes.

Although CRRT is a life-saving treatment, it has some disadvantages, such as requirement of technical expertise, follow-up of hemodynamic and coagulation parameters, and need for vascular access and anticoagulation. There are some limitations in newborn CRRT such as vascular access, bleeding complications, and a lack of neonatal-specific hemofiltration devices. In our country, small-size catheters and filters are not accessible. Therefore, we used $8 \mathrm{~F}$ catheters and large volume filters $\left(0.6 \mathrm{~m}^{2}\right)$. Blood priming was done before the starting the CRRT in our 13 newborn patients. A point to consider is that if blood priming is required, it may cause bradykinin release syndrome. Therefore, the CRRT machine was worked for $10 \mathrm{~min}$ for self-dialysis before being connected to the patient. In newborn patients, there were no complications when catheters were attached.

The most important complication in patients, especially newborns was low platelet count and anemia. Therefore, we prepared platelets and red blood cell suspensions for each patient before starting the dialysis. Coagulation with heparin was preferred. Citrate was not used in metabolic diseases. Our target for transfusion in the metabolic diseases was $<10 \mathrm{~g} / \mathrm{dL}$ for hemoglobin and $<50 \times 10^{3} / \mu \mathrm{L}$ for platelet count. Therefore, 31 of 36 patients were transfused. There was no severe bleeding in our patients because we closely followed vital signs, hematocrits and platelets. However, a patient with the diagnosis of UCD died as a result of thromboembolism, during the blood in the set being given back to the patient. In this study, blood pressure and other vital signs were followed closely. Therefore, blood pressures of our patients remained stable while CRRT use. In our study, most of the patients with UCD needed inotropic drugs (91.7\%). This may be due to high ammonia values. In addition, before the CRRT, arginine and intravenous sodium benzoate/phenyl butyrate were used, which may 
have reduced blood pressure. In our study, the mean arterial blood pressure values were not compared. Because of the different age group of the patients, blood pressure percentile changes according to age.

In this study, the overall survival rate was $88.9 \%$ in metabolic diseases with CRRT. Also, neonatal patients' survival rate was $84.6 \%$ (2/13 newborn). These rates were quite good, as in the literature [10]. Recently, Mok et al. reported CRRT mortality rate was 58\% in newborns with CRRT [5]. Importantly, the success rate of the MSUD patients was 100\% even though 6 newborns with CRRT use. In the CRRT patients without metabolic disease, the most important reason for high mortality could be sepsis and non-renal organ failures. In this group, eight patients (8/10) died during CRRT from refractory septic shock. In addition, 4 of these 8 patients were given the support of extracorporeal membrane oxygenation (ECMO).

\section{Limitations of the Study}

There are some limitations in the present study. It is a retrospective single-center and the long-term outcomes were not followed-up. The positive side of this study is that there are only a few published studies about CRRT for metabolic diseases in critically ill children. In addition, 36 patients were a relatively large population for metabolic diseases. Also, CRRT with low body weight and low age were other positive sides of this study.

\section{Conclusions}

Our results suggest that CRRT can effectively and quickly reduce plasma ammonia and leucine, particularly in hemodynamically unstable patients. Also, high dialysate flow rate does not increase the complications of CRRT in children. With an experienced team and close follow-up, CRRT is reliable and effective in critically ill patients, including those with low body weight.

Author Contributions: Conceptualization, F.A.; Data curation, F.A.; Formal analysis, F.A.; Funding acquisition, F.A.; Investigation, F.A.; Methodology, F.A.; Project administration, F.A.; Resources, F.A. and F.V.; Software, F.A.; Supervision, F.A. and H.C.; Validation, F.A. and C.A.-Z.; Visualization, F.V. and E.K.; Writing-original draft, F.A., E.K., and C.A.-Z.; Writing-review and editing, F.A. and C.A.-Z.

Funding: This research did not receive any specific grant from funding agencies in the public, commercial or not-for-profit sectors.

Conflicts of Interest: The authors have no conflicts of interest to disclose.

\section{References}

1. Boschee, E.D.; Cave, D.A.; Garros, D.; Lequier, L.; Granoski, D.A.; Guerra, G.G.; Ryerson, L.M. Indications and outcomes in children receiving renal replacement therapy in pediatric intensive care. J. Crit. Care 2014, 29, 37-42. [CrossRef] [PubMed]

2. Kim, J.Y.; Lee, Y.; Cho, H. Abstract Optimal Prescriptions of Continuous Renal Replacement Therapy in Neonates with Hyperammonemia. Blood Purif. 2019, 47, 16-22. [CrossRef] [PubMed]

3. Fakler, C.R.; Kaftan, H.A.; Nelin, L.D. Two cases suggesting a role for the L-arginine nitric oxide pathway in neonatal blood pressure regulation. Acta Paediatr. 1995, 84, 460-462. [CrossRef]

4. Kramer, P.; Wigger, W.; Rieger, J.; Matthaei, D.; Scheler, F. Arteriovenous haemofiltration: A new and simple method for treatment of over-hydrated patients' resistant to diuretics. Klin. Wochenschr. 1977, 55, 1121-1122. [CrossRef] [PubMed]

5. Wald, R.; Friedrich, J.O.; Bagshaw, S.M.; Burns, K.E.; Garg, A.X.; Hladunewich, M.A.; House, A.A.; Lapinsky, S.; Klein, D.; Pannu, N.I.; et al. Optimal Mode of clearance in critically ill patients with acute kidney injury (OMAKI) - A pilot randomized controlled trial of hemofiltration versus hemodialysis: A Canadian Critical Care Trials Group project. Crit. Care 2012, 16, R205. [CrossRef] [PubMed]

6. Phan, V.; Clermont, M.J.; Merouani, A.; Litalien, C.; Tucci, M.; Lambert, M.; Mitchell, G.; Jouvet, P. Duration of extracorporeal therapy in acute maple syrup urine disease: A kinetic model. Pediatr. Nephrol. 2006, 21, 698-704. [CrossRef] [PubMed] 
7. Spinale, J.M.; Laskin, B.L.; Sondheimer, N.; Swartz, S.J.; Goldstein, S.L. High-dose continuous renal replacement therapy for neonatal hyperammonemia. Pediatr. Nephrol. 2013, 28, 983-986. [CrossRef] [PubMed]

8. Cavagnaro Santa María, F.; Roque Espinosa, J.; Guerra Hernández, P. Continuous venovenous hemofiltration in neonates with hyperammonemia. A case series. Rev. Chil. Pediatr. 2018, 89, 74-78. [CrossRef] [PubMed]

9. Diane Mok, T.Y.; Tseng, M.H.; Chiang, M.C.; Lin, J.L.; Chu, S.M.; Hsu, J.F.; Lien, R. Renal Replacement Therapy in the Neonatal Intensive Care Unit. Pediatr. Neonatol. 2018, 59, 474-480. [CrossRef]

10. Zinnanti, W.J.; Lazovic, J.; Griffin, K.; Skvorak, K.J.; Paul, H.S.; Homanics, G.E.; Bewley, M.C.; Cheng, K.C.; Lanoue, K.F.; Flanagan, J.M. Dual mechanism of brain injury and novel treatment strategy in maple syrup urine disease. Brain 2009, 132, 903-918. [CrossRef]

11. Aygun, F.; Aygun, D.; Erbek Alp, F.; Zubarıglu, T.; Zeybek, C.; Cam, H. The impact of continuous renal replacement therapy for metabolic disorders in infants. Pediatr. Neonatol. 2018, 59, 85-90. [CrossRef]

12. Cho, H. Renal replacement therapy in neonates with an inborn error of metabolism. Korean J. Pediatr. 2018. [CrossRef]

13. McBryde, K.D.; Kudelka, T.L.; Kershaw, D.B.; Brophy, P.D.; Gardner, J.J.; Smoyer, W.E. Clearance of amino acids by hemodialysis in argininosuccinate synthetase deficiency. J. Pediatr. 2004, 144, 536-540. [CrossRef]

14. Häberle, J.; Boddaert, N.; Burlina, A.; Chakrapani, A.; Dixon, M.; Huemer, M.; Karall, D.; Martinelli, D.; Crespo, P.S.; Santer, R.; et al. Suggested guidelines for the diagnosis and management of urea cycle disorders. Orphanet. J. Rare Dis. 2012, 7, 32. [CrossRef]

15. Picca, S.; Dionisi-Vici, C.; Abeni, D.; Pastore, A.; Rizzo, C.; Orzalesi, M.; Sabetta, G.; Rizzoni, G.; Bartuli, A. Extracorporeal dialysis in neonatal hyperammonemia: Modalities and prognostic indicators. Pediatr. Nephrol. 2001, 16, 862-867. [CrossRef] [PubMed]

16. Hanudel, M.; Avasare, S.; Tsai, E.; Yadin, O.; Zaritsky, J. A biphasic dialytic strategy for the treatment of neonatal hyperammonemia. Pediatr. Nephrol. 2014, 29, 315-320. [CrossRef] [PubMed]

17. Gupta, S.; Fenves, A.Z.; Hootkins, R. The Role of RRT in Hyperammonemic Patients. Clin. J. Am. Soc. Nephrol. 2016, 11, 1872-1878. [CrossRef] [PubMed]

18. Yetimakman, A.F.; Kesici, S.; Tanyildiz, M.; Bayrakci, U.S.; Bayrakci, B.A. Report of 7-Year Experience on Pediatric Continuous Renal Replacement Therapy. J. Intensiv. Care Med. 2017. [CrossRef]

19. McBryde, K.D.; Kershaw, D.B.; Bunchman, T.E.; Maxvold, N.J.; Mottes, T.A.; Kudelka, T.L.; Brophy, P.D. Renal replacement therapy in the treatment of confirmed or suspected inborn errors of metabolism. J. Pediatr. 2006, 148, 770-778. [CrossRef]

20. Msall, M.; Batshaw, M.L.; Suss, R.; Brusilow, S.W.; Mellits, E.D. Neurologic outcome in children with inborn errors of urea synthesis. Outcome of urea-cycle enzymopathies. N. Engl. J. Med. 1984, 310, 1500-1505. [CrossRef] [PubMed]

21. Schaefer, F.; Straube, E.; Oh, J.; Mehls, O.; Mayatepek, E. Dialysis in neonates with inborn errors of metabolism. Nephrol. Dial. Transplant. 1999, 14, 910-918. [CrossRef] [PubMed]

22. Demirkol, D.; Şık, G.; Topal, N.; Çıtak, A.; Zeybek, Ç.; Tüten, A.; Bilge, I. Continuous Venovenous Hemodiafiltration in the Treatment of Maple Syrup Urine Disease. Blood Purif. 2016, 42, 27-32. [CrossRef] [PubMed]

(C) 2019 by the authors. Licensee MDPI, Basel, Switzerland. This article is an open access article distributed under the terms and conditions of the Creative Commons Attribution (CC BY) license (http://creativecommons.org/licenses/by/4.0/). 